LBL-36396

UC-1600

\title{
PHASE 2 OF THE CALIFORNIA HEALTHY BUILDING STUDY: A STATUS REPORT
}

\author{
William J. Fisk ${ }^{*}$, David Faulkner*, Mark J. Mendell ${ }^{\#}$, Doug Sullivan*, Alfred T. \\ Hodgson*, Janet M. Macher ${ }^{+}$, Michael Boyle*, Katherine Chow*, Joan M. Daisey*, \\ Francis J. Offermann', Steven Loiselle ${ }^{\dagger}$
}

\author{
*Indoor Environment Program \\ Energy and Environment Division \\ Lawrence Berkeley Laboratory \\ University of California \\ Berkeley, CA 94720 \\ \#Industrywide Studies Branch \\ National Institute for Occupational Safety and Health \\ Centers for Disease Control \\ Cincinnati, OH 45226 \\ +Indoor Air Quality Program \\ Environmental Health Laboratory \\ California Department of Health Services \\ Berkeley, CA 94704 \\ 'Indoor Environmental Engineering \\ San Francisco, CA 94109
}

November 1994

This research was supported by the Assistant Secretary for Energy Efficiency and Renewable Energy, Office of Building Technologies, Building Systems and Materials Division of the U.S. Department of Energy (DOE) under Contract No. DE-AC0376SF00098, and by the National Institute for Occupational Safety and Health of the U.S. Centers for Disease Control and Prevention.

\section{MASTER}




\section{DISCLAIMER}

This report was prepared as an account of work sponsored by an agency of the United States Government. Neither the United States Government nor any agency thereof, nor any of their employees, make any warranty, express or implied, or assumes any legal liability or responsibility for the accuracy, completeness, or usefulness of any information, apparatus, product, or process disclosed, or represents that its use would not infringe privately owned rights. Reference herein to any specific commercial product, process, or service by trade name, trademark, manufacturer, or otherwise does not necessarily constitute or imply its endorsement, recommendation, or favoring by the United States Government or any agency thereof. The views and opinions of authors expressed herein do not necessarily state or reflect those of the United States Government or any agency thereof. 


\section{DISCLAIMER}

Portions of this document may be illegible in electronic image products. Images are produced from the best available original document. 


\section{ABSTRACT}

The primary goal of the California Healthy Building Study (CHBS) is to identify the major characteristics of buildings, ventilation systems, jobs, and indoor environmental quality that are associated with building-related sick-building health symptoms. The first phase of the CHBS was a cross sectional study of 12 office buildings located in the San Francisco Bay area. Health symptom and job data were collected via a questionnaire, buildings and ventilation systems were characterized, and regression models were used to assess associations between symptom prevalences and factors suspected to be associated with increased symptoms. This report summarizes research activities undertaken during Phase- 2 of the CHBS and compiles currently available results. Phase 2 activities were limited to inspections and low cost measurements that yielded additional information that could be used in conjunction with the Phase-1 symptom data or provided valuable experience or information for future research. Because much of the Phase-2 effort was devoted to evaluation of measurement methodologies or collection of information that will be used in conjunction with the Phase-1 symptom data, this report is intended primarily for internal use by the CHBS research team. The Phase-2 study included the following components: (1) inspections of HVAC systems to identify and, in some cases, quantify potential sources of volatile organic compounds, fibers, and bioaerosols; (2) evaluation of a protocol for measuring the concentration of bioaerosols in the air exiting supply air diffusers; (3) interviews of building operators to assess practices related to HVAC inspection, cleaning, and disinfecting; (4) evaluation of a protocol for measuring the extent of microbiological contamination on floors and on upholstered chairs; (5) quantifying the amount of carpet within each study space in order to allow an improved assessment of associations with worker symptoms; (6) interviews of building operators to determine the quality of office cleaning and the nature of office pest-control practices; (7) measurement of the spatial and temporal variations in sound levels within study areas so that a protocol for sound-level measurements could be designed and used in a future study; and (8) measurement of percent lighting flicker in each study space so the association between percent flicker and symptoms could be evaluated. Regression modeling to evaluate associations between Phase- 1 symptom prevalences and Phase-2 data is ongoing and is not described in this document.

\section{INTRODUCTION}

\section{Background}

The phenomenon of "sick building syndrome" (SBS) is now widely recognized as a significant problem by public health officials, researchers, and the general public. Incidents of SBS, within specific buildings (often office buildings) are characterized by an unusually high prevalence of health symptoms and health complaints among the buildings' occupants. The symptoms may include irritation of the eyes, nose or throat, dry or itchy skin, difficulty breathing, cough, headache and fatigue. These symptoms could have many potential causes and, therefore, do not generally indicate a specific disease or 
specific pollutant exposure. The occupants believe that their symptoms are caused by the indoor environment, generally by air pollution within the building. They report that their symptoms improve when they are not in the building, unlike the symptoms associated with typical infectious diseases. Severe cases of SBS prompt investigations by health officials and consultants and can even lead to evacuation of buildings.

During the past ten years, researchers have started to use cross-sectional surveys conducted in multiple office buildings (chosen irrespective of the prevalence of occupant complaints) to evaluate the associations between the prevalences of health symptoms and characteristics of the individual, job, work space, building, and indoor environment. Questionnaires are used to determine the prevalences of health symptoms and to collect information on the individuals and their jobs and workspaces. Inspections and measurements are the basis for information on buildings and environmental conditions. These surveys have shown that many occupants of "normal buildings", (i.e., buildings without identified sick-building problems) report that they have health symptoms that improve when they are away from the building. They report the same symptoms commonly associated with SBS. An increased prevalence of symptoms in occupants of mechanically-ventilated buildings with air conditioning relative to the prevalence in occupants of naturally-ventilated buildings is the strongest and most consistent association identified in these surveys. Prior to Phase 1 of the California Healthy Building Study (described below), no cross-sectional survey of this type had been completed in U.S. buildings.

\section{Summary of the Phase 1 Study}

In the summer of 1990 , we completed a survey in twenty-nine study spaces within twelve city- or county-owned office buildings located in the San Francisco area. The study methods are described in detail by Daisey, et al. (1990). Results are documented in Mendell (1991), Mendell, et al. (1993); and Fisk, et al. (1993). An investigation of the association between symptom prevalence and ventilation type was a primary goal. Six of the buildings were air conditioned (AC) and had sealed windows. Three buildings were mechanically ventilated (MV) without air conditioning and had openable windows. The remaining three buildings were naturally ventilated (NV) with openable windows. Smoking was prohibited in all buildings except in designated smoking lounges. 880 occupants provided information on their symptom prevalences, jobs, and workspaces, and provided personal information (e.g., sex, age, and smoking status). Occupants reported their symptom prevalences during the previous week and previous year and indicated if symptoms improved when they were away from the building. Building and ventilation system characteristics were determined in inspections and interviews with building operators. Several indoor environmental parameters were measured during the week that preceded questionnaire administration. The time-average indoor and outdoor concentrations of $\mathrm{CO}_{2}$ and $\mathrm{CO}$ for the 45 -hour work week were measured. The average indoor air temperature and humidity during each 15 -minute period were recorded. Indoor and outdoor samples were collected for one work day and analyzed for determination of the total concentration of volatile organic compounds (TVOC) and to determine the 
concentrations of individual VOCs: Short-term (e.g., few minute) indoor and outdoor samples were also collected on a single day for a determination of the concentrations of total airborne viable fungi and bacteria. Measurements of aldehyde concentrations and ventilation rate, using new methods, were attempted but unsuccessful.

Logistic regression models were used to evaluate the associations between prevalences of work-related symptoms (i.e., symptoms that improve when away from work) and characteristics of the buildings, jobs, workspaces, individuals, and indoor environment. Each model yields odds ratios for various risk factors related to occurrence of a specific symptom. The odds ratio is defined as the odds for a symptom in the population of individuals with a hypothesized risk factor (e.g., individuals in an AC building) divided by the odds for the same symptom in a reference population of individuals without that risk factor (e.g., individuals in a NV building). The model computes odds ratios while controlling simultaneously for multiple confounding factors; for example, controlling the difference in gender distributions between two populations.

The Phase-1 data indicated that occupants of the air-conditioned and mechanicallyventilated buildings had an increase in the prevalence of most symptoms relative to occupants of naturally-ventilated buildings (Mendell, et al. 1993), although there was substantial variation in symptom prevalence between buildings with the same type of ventilation. The odds ratios for skin symptoms (dry or itchy skin) and tight chest and difficulty breathing were more highly elevated in the buildings with AC and MV than the odds ratios for other symptoms (eye, nose, and throat irritation; headache; fatigue or sleepiness). The finding of increased symptoms in air conditioned buildings is particularly significant because it is consistent with the results of previous European surveys (Mendell and Smith 1990). We know that ventilation type cannot be a direct cause of symptoms, so it must be a surrogate for one or more direct causes such as an increased pollutant exposure.

Several other factors were associated with increased prevalence of one or several symptoms. These factors include female gender, high job stress (reported on the questionnaire), use of carbonless copies, any carpet in the test space, and lack of a window within 15 feet of the workstation. Based on data analyses to date, no measured environmental parameter was clearly associated with an increase in symptom prevalence. An increase in the prevalence of several symptoms among occupants with the highest quartile of airborne viable fungi was suggested; however, buildings with the highest fungi concentrations were also the oldest buildings, and the proper interpretation of this association is unclear.

\section{Objectives of Phase 2 of the California Healthy Building Study}

Due to limited resources and time, Phase 2 activities were limited to inspections and low cost measurements that: (1) yielded information that could be used in conjunction with the Phase-1 symptom data; or (2) provided valuable experience or information for future research. To meet the first of these two criteria, we needed to be reasonably certain that 
the information collected during Phase 2 was also representative of the Phase- 1 period (June through September of 1990), when the Phase-1 symptom data were collected. Phase 2 activities that met the second criterion were primarily evaluations of measurement methods or procedures for collecting information on the HVAC systems or buildings.

\section{CHBS PHASE 2: METHODS AND RESULTS}

Phase 2 data collection occurred between approximately October 1992 and March 1993. This report describes the research activities during Phase 2 and summarizes currently available results of analyses of Phase- 2 data. Because much of the Phase- 2 effort was devoted to evaluation of measurement methodologies or collection of information that will be used in conjunction with the Phase-1 symptom data, this report is intended primarily for internal use by the CHBS research team.

The remainder of this document is organized into sections for each of the hypotheses that motivated the Phase 2 activities. After listing each hypothesis, we provide background information justifying the hypothesis, describe the Phase 2 activities, and then summarize the findings to date. A document describing the designs of Phase- 2 and a potential Phase 3 of the CHBS (Fisk, et al., 1992) provides more detailed information on the procedures employed.

During the period of Phase- 2 data collection, research activities were completed on a subset of the set of hypotheses discussed in Fisk, et al. (1992). Consequently, this document only discusses research activities connected to hypotheses $1,2,8$, and 9 .

\section{Hypothesis 1: HVAC systems can be a source of pollutants that elicit symptoms. The potential pollutants are VOCs, microorganisms, and fibers.}

\section{a. Background}

Mechanical ventilation with air conditioning, relative to natural ventilation, has been associated with an increased prevalence of work-related symptoms in Britain (Mendell and Smith 1990), Denmark (Skov, et al., 1987), United States (Fisk, et al., 1993), Finland (Jaakkola, et al., 1993), and Greece ( Balaras, et al., 1993). Despite these largely consistent findings, mechanical ventilation per se with or without air conditioning cannot be a direct cause of symptoms. Instead, it must be a surrogate for other agents or environmental conditions that elicit symptoms. One possibility is that HVAC systems are sources of pollutants that are transported to the occupied spaces and then elicit symptoms. HVAC systems contain several potential sources of contaminants. Interior duct liners used for thermal insulation and sound adsorption and fiberglass ducts are present in many HVAC systems and are potential sources of fibers and VOCs. Chemicals and cleaning compounds are sometimes stored in mechanical rooms or fan rooms -- another potential source of VOCs. HVAC systems also contain many sites suitable for colonization by 
microorganisms, such as wet coils, drain pans, air filters, humidifiers (although no Phase 1 building has a humidifier), and dirty duct liners or duct surfaces. Fanger, et al. (1988) conducted surveys which indicated, through subjective perceptions of trained panels of people, that HVAC systems are a significant source of air pollution.

We have generated four sub-hypotheses related to Hypothesis 1 . In the following sections we state these sub-hypotheses and describe the associated research activities.

\subsection{Hypothesis 1, Sub-hypothesis 1: Ventilation systems are a source of VOCs that elicit symptoms.}

\section{a. Background}

In the Phase 1 investigation, eye, nose or throat symptoms were the most common symptoms among the entire study group of 880 workers ( 40 percent reported one of these symptoms). The prevalence of fatigue or sleepiness was also quite high ( 33 percent). For workers in air conditioned and mechanically ventilated buildings, many building-related symptoms were elevated compared to naturally ventilated buildings, with the highest adjusted odds ratios associated with skin symptoms, chest tightness or difficulty breathing, and chill or fever (Mendell, et al., 1993).

A possible explanation for the finding that symptoms were elevated in air-conditioned and mechanically ventilated buildings relative to naturally ventilated buildings, is that ventilation systems are a source of increased airborne chemical contaminants. Some research on emissions of chemicals by HVAC systems has been reported. Molhave and Thorsen (1991) used a mass-balance approach in an attempt to show that ventilation systems are a primary source of VOCs. Recently, Sundell, et al. (1993) compared TVOC concentrations in intake (outside) air and supply air within multiple buildings and rooms. In 37 cases, supply-air TVOC concentrations were higher than intake air concentrations. If the supply air did not contain recirculated indoor air, these data would indicate that the HVAC system were a source of VOCs; however, the authors do not indicate how many of these building ventilation systems recirculated air. In 28 cases, the concentrations "did not differ" and in 21 cases the supply air had a lower TVOC concentration than intake air. The authors hypothesized that the reductions in TV.OC concentrations were due to chemical reactions that may have produced new VOCs not accounted for in the TVOC measurement.

One common material which is a potential source of VOCs in air handling systems is internal duct liner used as a thermal insulation and for noise control, generally in the region near fans and coils. Other potential VOC sources in air handling systems are fiberglass-lined duct and fiberglass duct. Fiberglass-lined duct is not clearly distinguished from duct liner but is generally considered to be ductwork, more distant from fans and coils, with a sheet metal outer skin with an inner layer of fiberglass insulation. Fiberglass duct is a newer type of duct constructed of fiberglass without a layer of sheet metal. 


\section{b. Objectives}

The primary objectives of this investigation during Phase 2 were to identify the HVAC systems containing duct liner and to determine if aged duct liners obtained from the study buildings are a significant primary source of individual VOCs and low-molecular weight aldehydes.

\section{c. Methods}

The 27 air handling units serving the study spaces within the twelve buildings were inspected using the protocol and inspection forms described in Appendices 2 and 3 of Fisk, et al. (1992). During the inspections, the presence or lack of internal duct liner was noted on the inspection forms and the surface area of duct liner was estimated when possible. A sample of each type of duct liner, approximately $10 \mathrm{~cm}$ by $10 \mathrm{~cm}$ in area, was collected, placed in a sealed container, and stored in a freezer. Plans for subsequent analyses of VOC emissions from these samples are described in Fisk, et al. 1992. The building operators were asked about the presence of fiberglass-lined duct and fiberglass duct in the building.

\section{d. Results}

The presence of duct liner in each air handler is indicated in Table 1 and an estimate of the total surface area is provided when available. The presence of fiberglass-lined or fiberglass duct is also noted. Duct liner was present in 21 of 27 air handlers. Fiberglasslined duct was confirmed in six air handlers. Due to limited resources, the rates of emissions of VOCs from the duct liner samples have not yet been determined. 
Table 1. Information on duct liners and fiberglass ducts in the air handlers. (ND indicates that no data are available, NA indicates not applicable.)

\begin{tabular}{|c|c|c|c|c|c|c|}
\hline $\begin{array}{l}\text { Build- } \\
\text { ing \# }\end{array}$ & Air Handler ID & $\begin{array}{c}\text { Study Spaces } \\
\text { Affected }\end{array}$ & $\begin{array}{c}\text { Estimated Area } \\
\text { of Duct Liner } \\
\left(\mathrm{m}^{2}\right)\end{array}$ & $\begin{array}{c}\text { Visible } \\
\text { Damage to } \\
\text { Duct Liner } \\
\text { Yes/No/ND } \\
\end{array}$ & $\begin{array}{c}\text { Fiberglass or } \\
\text { Fiberglass- } \\
\text { Lined Duct } \\
\text { Yes/No/ND } \\
\end{array}$ & Comment \\
\hline 2 & SF1, EF1 & 021,022 & 0 & $\mathrm{NA}$ & No & 1 \\
\hline 2 & $\begin{array}{c}\text { SF2, EF2A } \\
\text { EF2B }\end{array}$ & $021^{*}, 022^{*}$ & 6 & yes & No & 2 \\
\hline 3 & SF1, EF1 & $031,032,033$ & $\begin{array}{c}\text { Present, } \\
\text { Unquantified }\end{array}$ & No & ND & 1 \\
\hline 3 & SF2, EF2 & $031,032,033$ & $\begin{array}{c}\text { Present, } \\
\text { Unquantified }\end{array}$ & No & $\mathrm{ND}$ & 1 \\
\hline 3 & $\mathrm{ACl}$ & $031,032,033$ & $>14$ & No & No & \\
\hline 3 & $\mathrm{AC2}$ & $031,032,033$ & $>14$ & No & No & \\
\hline 4 & Large W. AHU & $041,042,043$ & 74 & Yes & Yes, extensive & \\
\hline 4 & Large E. AHU & $041^{+}, 042^{+}, 043^{+}$ & 74 & No & Yes, extensive & \\
\hline 4 & Small E. AHU & $041^{+}, 042^{+}, 043^{+}$ & 1 & No & No & \\
\hline 4 & Small NE AHU & $041^{+}, 042^{+}, 043^{+}$ & 2 & No & No & \\
\hline 5 & AHU1 & $051^{+}, 052^{+}, 053^{+}$ & 22 & Yes & ND & \\
\hline 5 & AHU2 & $051,052,053$ & 0 & NA & $\mathrm{ND}$ & \\
\hline 5 & AHU3 & $051^{\#}, 052^{\#}, 053^{\#}$ & $\begin{array}{c}\text { Present, } \\
\text { Unquantified }\end{array}$ & No & ND & \\
\hline 5 & AHU4 & $051^{+}, 052^{+}, 053^{+}$ & 0 & $\mathrm{NA}$ & No & \\
\hline 5 & Aux. Fl. 2 AHU & 051 & ND & ND & No & \\
\hline 5 & Aux. Fl. $3 \mathrm{AHU}$ & 052 & $\mathrm{ND}$ & $\mathrm{ND}$ & No & \\
\hline 5 & Aux. Fl. $6 \mathrm{AHU}$ & 053 & $\mathrm{ND}$ & $\mathrm{ND}$ & No & \\
\hline 6 & AHU 10 & 061 & 31 & No & No & 3 \\
\hline 6 & AHU11 & 061 & 31 & No & No & 3 \\
\hline 7 & Roof Top North & 071,072 & 90 & No & Yes & 1,4 \\
\hline 7 & Roof Top South & $071,072^{+}$ & 90 & No & Yes & 1,4 \\
\hline 7 & Basement & $071^{+}, 072^{+}$ & 0 & $\mathrm{NA}$ & No & \\
\hline 8 & System 1 & 081,082 & 0 & NA & Yes, Partial & 1 \\
\hline 9 & $S 1^{\wedge}$ & $091,092,093,094$ & 11 & No & Yes & \\
\hline 9 & $S 2^{\wedge}$ & $091,092,093,094$ & 55 & No & ND & \\
\hline 9 & $S 3^{\wedge}$ & $091,092,093,094$ & 55 & No & ND & \\
\hline 11 & FSB 1 & 111 & 0 & NA & No & \\
\hline
\end{tabular}

Comments:

1. Contains sound silencers, a potential source of VOCs and fibers

2. Return fan compartment contains batts of fiberglass insulation and loose spray-on cellulose insulation.

3. Units have common return fan and return duct.

4. Duct liner area includes estimated area of lining in supply ducts.

Footnotes: *AHU indirectly affects study spaces via mechanical recirculation

+ AHU may indirectly affect study spaces due to indoor airflow

\# unused AHU, expect limited impact on study spaces due to unintentional airflow

$\wedge$ specific areas served by each AHU not determined but study spaces connected by stairwells 


\subsection{Hypothesis 1, Sub-hypothesis 2: HVAC systems can be sources of bioaerosols that elicit symptoms.}

\section{a. Background}

The growth of microorganisms within HVAC systems has been well documented (e.g., see Burge 1990, Morey, et al., 1990, Morey and Williams 1991; Martikainen, et al., 1990, Elixmann, et al., 1990). Sites within HVAC systems where microbiological growth can occur include coils, drain pans of cooling coils, air filters, internal fibrous duct liner, dirty interior surfaces of ducts without an internal liner, humidifiers, and cooling towers. In some cases, airborne microorganisms emitted from HVAC systems have clearly been associated with specific illnesses, such as Legionnaires disease. However, the extent to which microbiological growth in HVAC systems is a cause of the less severe and varied symptoms associated with sick building syndrome, or a cause of the same symptoms in non-sick buildings, has not been determined. Clearly, the hypothesis that HVAC systems are a source of bioaerosols that elicit symptoms is plausible. Microorganisms can multiply in HVAC systems, the flow of air in the HVAC systems provides a means of transport to the occupied space; and inhaled microorganisms, along with volatile microbiological by-products and other biologic materials can trigger hypersensitivity reactions such as allergic rhinitis (Burge 1990, Burge, et al., 1987, Hood 1990, Morey, et al., 1990). Even without active growth in the HVAC system, bioaerosols and other debris that have collected in an HVAC system may be re-suspended when the system is disturbed vigorously or when it first is turned on after a period of non-use. The supply air then may carry this material into a building.

\section{b. Objectives}

In Phase 2, our primary objective was to evaluate protocols relevant for testing the hypothesis that HVAC systems can be a source of bioaerosols that elicit health symptoms. One set of protocols contains proposed methods (primarily an inspection protocol) for identifying microbiological contamination in HVAC systems. Another protocol is a method for determining if bioaerosols exit the supply air diffusers which are the final component of the HVAC system (in the supply air) upstream of the occupied space.

\section{c. Methods}

The 27 air handling units serving the study spaces within the twelve buildings were inspected using the protocol and inspection forms described in Appendices 2 and 3 of Fisk, et al., (1992). The inspectors received training from a microbiologist in the visual identification of microbiological contamination and were instructed to collect samples of suspected fungal or bacterial contamination for analyses in the laboratory. For reference, samples were also to be collected from areas within the air handlers without visual evidence of contamination. 
Limited experience was also gained in collection of bioaerosol samples from the supply air exiting supply air diffusers in three buildings. For approximately eight hour periods, samples were drawn from supply air jets through a short section of tubing and through 0.4 $\mu \mathrm{m}$ (pore size) polycarbonate filters. The sampling rate (approximately $3 \mathrm{lpm}$ ) and tube diameter and placement were selected to make sampling roughly isokinetic. To obtain information on measurement precision, multiple samples were collected from different locations in supply air jets exiting each supply diffuser and samples were collected from air exiting three diffusers in each building. The same method was used to simultaneously collect samples in the outside air entering the air handlers. After completing sample collection, the polycarbonate filters were washed with sterile water and the suspensions were re-filtered on cellulose membrane filters which were placed directly on culture media. The two culture media were malt extract agar, a medium recommended for the recovery of saprophytic fungi, i.e., those that grow on decaying organic matter (Burge and Solomon 1987, Burge, et al., 1987, Burge, et al., 1989, Burge 1990) and malt extract agar with 100 grams of sodium chloride added per liter volume. The addition of sodium chloride as suggested by Flannigan (1992) yields a culture medium more suitable for growth of xerophilic fungi, i.e., fungi that survive best in less moist environments. Flannigan (1992) has discussed the potential importance of xerophilic fungi in indoor environments. The plates were incubated at $20-25^{\circ} \mathrm{C}$. The types of fungal colonies that grew on the culture media were classified as described in Appendix 5 of Fisk, et al. (1992).

One potential limitation of the sampling method must be mentioned. Some types of fungi may not survive the sampling process due to the drying that occurs when air is drawn through the polycarbonate filter for an extended period. Hence, the sampling process could lead to erroneously low measurements of the concentrations of some fungi. However, many fungi are expected to survive the sampling process and we are unaware of a better protocol for extended-term sampling. The most common sampling method, impaction of bioaerosols onto culture media, is suitable for sample periods less than approximately 10 minutes. To complement these field trials, laboratory experiments have been completed to evaluate loss of viability during sampling of fungi on filters; however, the analyses of the data have not been completed.

\section{d. Results}

The concentrations of culturable fungi in the outside air and supply air are summarized in Table 2. Concentrations in the outside air were typically a factor of ten to 100 greater than concentrations in the supply air, presumably because the supply air system filters out many of the fungi. The low concentrations in the supply airstreams also suggest that the air handlers were not large sources of total culturable fungi during the periods of sample collection. Due to the potential death of some types of fungi during sampling, we could have failed to detect the release of some types of fungi by the air handlers. Because of the statistical uncertainty in the supply air fungal concentrations (a consequence of the low concentrations), we could not quantify the spatial variability in fungal concentrations at specific supply diffusers or between different diffusers in the same building. 
Table 2. Concentrations of total culturable fungi in outside air and air exiting supply diffusers. Results of samples collected simultaneously from the same supply diffuser are separated by commas.

\begin{tabular}{|c|c|c|c|}
\hline Building \# & Site & $\begin{array}{c}\text { Total Culturable Fungi on } \\
\text { MEA }\left(\mathrm{cfu} \mathrm{m}^{-3}\right)\end{array}$ & $\begin{array}{c}\text { Total Culturable Fungi on } \\
\text { MEA-NACL }\left(\mathrm{cfu} \mathrm{m} \mathrm{m}^{-3}\right)\end{array}$ \\
\hline 2 & outside air & 1500 & 120 \\
\hline 2 & diffuser \#1 & 12 & 18,8 \\
\hline 2 & diffuser \#2 & 14 & 9,12 \\
\hline 2 & diffuser \#3 & 18 & 6 \\
\hline 3 & outside air & 100 & 88 \\
\hline 3 & diffuser \#1 & 1,4 & 2 \\
\hline 3 & diffuser \#2 & 2 & 2,2 \\
\hline 3 & diffuser \#3 & 2 & 7 \\
\hline 4 & outside air & 490 & 9 \\
\hline 4 & diffuser \#1 & 18,20 & 19 \\
\hline 4 & diffuser \#2 & 32,9 & 20 \\
\hline 4 & diffuser \#3 & 42 & 9 \\
\hline
\end{tabular}

\subsection{Hypothesis 1, Sub-hypothesis 3: HVAC systems are a source of fibers that elicit skin and mucus-membrane symptoms. Consequently, the surface area of potential fiber sources in HVAC systems is also related to symptom prevalence.}

\section{a. Background}

In the Phase 1 study, occupants of mechanically-ventilated (MV) and air conditioned (AC) buildings had a much higher prevalence of dry or itchy skin than occupants of naturally-ventilated buildings. The associated odds ratios (and 95\% confidence intervals) were $5.8(1.9-18)$ and $5.6(1.9-16)$ for the MV and AC buildings, respectively. Low humidities, below roughly $30 \%$ relative humidity, are considered a source of skin symptoms, but the measured humidities were well within the range considered acceptable (week-average relative humidity ranged between $42 \%$ and $56 \%$ ). Most air pollutants are not known to be a source of skin symptoms. However, fibers are a known source of skin irritation and could be emitted by the HVAC systems present in the MV and AC buildings. Potential sources of fibers inside HVAC systems are internal fibrous duct liners (used near fans and coils for thermal insulation and sound adsorption) and fiberglass-lined or fiberglass ductwork. Fibers in these materials may contact the moving air if there is not a continuous membrane between the fibers and the air stream. The moving air is a means of transport of fibers to the occupied space. In addition, the ductwork of many HVAC systems is insulated with external fiberglass insulation. This external insulation is generally surrounded by a layer (vapor barrier) of metal foil, paper, or plastic that should help to contain the fibers. However, fiberglass could escape into the indoor environment where the vapor barrier is broken and at the edges of fiberglass batts. Furthermore, fibers that are released during initial installation of the insulation could have 
accumulated on surfaces (e.g., in ceiling plenums) and, upon disturbance or vibration, enter the occupied space.

We are unaware of attempts to evaluate the association between these potential sources of fibers and symptom prevalence. Some data exist on fiber emission rates from these sources. Gamboa,et al. (1988) conducted laboratory tests to evaluate the emissions of fiberglass fibers from fiberglass duct liner and fiberglass duct board. The new fiberglass materials assembled in accordance with an industry standard were not a significant source of airborne fibers; however, the implications for fiber emissions in older field settings are unclear. Laboratory and field tests by Shumate and Wilhelm (1991) of fiber emissions from fiberglass air filters indicated that emissions from the filters were negligible. Data on concentrations of fibers in air and on surfaces in Danish buildings is provided by Schneider (1986) and Schneider, et al. (1990). These references indicate the airborne concentrations of fibers are low compared to accepted standards and indicate that measurements of fibers on surfaces may be more relevant. The low airborne concentrations may be attributed to the rapid setting of the fibers and the episodic release of fibers that are not reflected in air samples. Because HVAC systems are not the only possible fiber sources in buildings (ceiling tiles, wall insulation, and fireproofing are other potential sources), an evaluation of the correlation between symptoms and the concentrations of fibers on surfaces or in air is relevant but not a direct test of this hypothesis.

Recently, Hedge, et al. (1993) reported a correlation between health symptoms and the concentration of man made mineral fibers in dust. Only one of nine buildings had a high fiber concentration; therefore, the reported association may simply be coincidental.

\section{b. Objectives and Methods}

During Phase 2, we inspected the air handling systems serving each study space (using the protocol described previously in this document) to determine if internal duct lining with fibers is present and, when possible, to determine the surface area of duct lining. We also asked the building operators about the presence of fiberglass-lined and fiberglass ducts in the air handling systems serving the study spaces.

\section{c. Results}

The presence or lack of duct liner in each air handling system is indicated in Table 1. An estimate of the surface area of duct liner is provided when available. The presence of fiberglass duct or duct with internal fiberglass insulation are also noted. Duct liner was present in 21 of 27 air handlers. Fiberglass lined duct was confirmed in six systems. Damage to internal duct liner, which would increase the potential for release of fibers, was visible in three air handlers. We have not yet assessed associations between these potential sources of fibers and skin irritation symptoms. 


\subsection{Hypothesis 1, Sub-hypothesis 4: Poorly cleaned HVAC systems can be sources of contaminants that elicit symptoms.}

\section{a. Background}

Poor ventilation system maintenance might affect worker symptoms through either increased contamination of ventilation air (from poor system cleaning), inadequate outside air delivery (from poor system balancing, adjustment, or operation), or diminished thermal comfort (also from poor system balancing, adjustment, or operation). Other measures planned in future studies will assess the latter two effects more directly (e.g., local measures of ventilation rate and temperature/humidity). This protocol assessed only those maintenance aspects relevant to potential contamination of ventilation air -activities of inspection, cleaning, and disinfecting.

We have identified no previous assessments of the relationship between symptoms and HVAC cleaning practices. One study found no association between symptoms and a crude rating of HVAC system cleanliness (Burge, et al., 1987). However, a follow-up of buildings from this study found that among two pairs of buildings, the buildings with lower symptom prevalence had better standards of maintenance (Burge 1990). Cleanliness rather than cleaning practices were assessed in the first study, and in the latter study, the focus seems to have been more on proper operation of the system than on system cleanliness.

\section{b. Objectives}

There were two primary objectives regarding the HVAC system cleaning assessment: first, to test an interview protocol for assessing mechanical ventilation system cleaning within study buildings; and second, to identify aspects of mechanical system cleaning procedures, if any, which correlate with worker symptom reports.

\section{c. Methods}

The assessment interview was first pilot tested in a non-study building, and then revised. The revised assessment was carried out in the nine (of 12) study buildings which have mechanical ventilation systems. Within the nine buildings, 27 air handlers with potential impacts on the Phase 1 study spaces were inspected. Information for this protocol was collected by interview with appropriate building personnel, by inspection of necessary documents, and by direct inspection of relevant system components. The protocol was constructed to ascertain HVAC cleaning practices retrospectively, for the time of the 1990 Phase 1 study. Information collected by the HVAC system cleaning assessment protocol was summarized to describe the range of HVAC cleaning practices in our population of study buildings. Data on HVAC system cleaning practices, considered to reflect potential risk of HVAC contamination, will be compared with symptoms reported by workers in the study buildings during the 1990 Phase 1 study. Both univariate and adjusted multivariate methods will be used. (A few preliminary analyses have been completed.) 


\section{d. Results}

Not all of the data collected were considered usable in analyses. The interviewers felt that in many of the buildings, descriptions of maintenance activities were influenced by what the operators felt were "desired" answers. From their later inspections, the interviewers suspected that most of the HVAC components we asked about were not actually included in regular inspection and cleaning schedules, even if such inclusion was sometimes reported. The specific components judged to be actually included in regular inspection and cleaning schedules were: filters, drain pans, and heating and cooling coils. Furthermore, for many of the questions, data were too incomplete to use; and for others (such as inspection and replacement of filters) there was insufficient variation across buildings for use in analyses.

We restricted our analyses to the following questions thought to be most useful and accurate:

1) Is there a written schedule for HVAC maintenance and cleaning?

2) Are there written records of past HVAC inspection and cleaning?

3) Are anti-microbial compounds used in the cooling coil drip pans?

4) Is there regular inspection of cooling coil drip pans?

The answers to these questions in the study buildings are summarized in Table 3 . Unadjusted analyses thus far indicate that all of these potential indicators of poor HVAC maintenance are significantly associated with increases in at least some work-related symptoms. Multivariate analyses to confirm these relationships are ongoing.

Table 3. Results of assessment of HVAC cleaning practices.

\begin{tabular}{|c|c|c|c|c|}
\hline $\begin{array}{l}\text { Building ID } \\
\text { Number } \\
\text { (HVAC } \\
\text { Type*) }\end{array}$ & $\begin{array}{l}\text { Written Schedule } \\
\text { for HVAC } \\
\text { Maintenance and } \\
\text { Cleaning? }\end{array}$ & $\begin{array}{l}\text { Written Records } \\
\text { for HVAC } \\
\text { Maintenance } \\
\text { and Cleaning? }\end{array}$ & $\begin{array}{l}\text { Anti-Microbials } \\
\text { Used in Coil } \\
\text { Drip Pans? }\end{array}$ & $\begin{array}{l}\text { Regular } \\
\text { Inspection of } \\
\text { Coil Drip } \\
\text { Pans? }\end{array}$ \\
\hline $1(\mathrm{NV})$ & not applicable & not applicable & not applicable & not applicable \\
\hline $2(\mathrm{AC})$ & no & no & no & no \\
\hline $3(\mathrm{AC})$ & yes & yes & yes & no \\
\hline $4(\mathrm{AC})$ & no & yes & no & no data \\
\hline $5(\mathrm{AC})$ & no & yes & no & yes \\
\hline $6(\mathrm{MV})$ & yes & yes & not applicable & not applicable \\
\hline $7(\mathrm{AC})$ & yes & yes & yes & no \\
\hline $8(\mathrm{AC})$ & yes & yes & yes & no \\
\hline 9 (MV) & yes & yes & not applicable & not applicable \\
\hline $10(\mathrm{NV})$ & not applicable & not applicable & not applicable & not applicable \\
\hline $11(\mathrm{MV})$ & no & no & not applicable & not applicable \\
\hline $12(\mathrm{NV})$ & not applicable & not applicable & not applicable & not applicable \\
\hline
\end{tabular}


2. Hypothesis 2: Occupants are exposed to pollutants that accumulate on indoor surfaces, especially high surface area materials. The suspected pollutants are viable and non-viable microorganisms and fibers. The exposure route may involve direct human contact with the surfaces or resuspension and inhalation of particles.

\section{a. Background}

Based on physiology, exposure to pollutants is a logical cause of the health symptoms associated with SBS. However, the prior surveys that included air pollutant measurements and assessments of symptom prevalence have identified no consistent statistically-significant associations between air pollutant concentrations and symptom prevalences. The prior surveys do provide some direct and indirect evidence for an association between pollutants on surfaces and symptoms as described in the discussion of Sub-hypotheses $2.1-2.3$.

We have generated three sub-hypotheses related to Hypothesis 2. In Sections 2.1 through 2.3, we state these sub-hypotheses and describe the associated research activities.

2.1. Hypothesis 2, Sub-hypothesis 1: Occupants are exposed to viable and nonviable microorganisms that accumulate on floors or chairs. The exposure route may involve episodic resuspension and inhalation or direct contact with skin and transport via hands to mucous membranes. These exposures may elicit symptoms in some individuals.

\section{a. Background}

Dust that has accumulated on horizontal surfaces (such as floors) within a building may be better than air samples as an indicator of the bioaerosols that have been in the building in the past. Horizontal surfaces, especially those with a high surface area, such as carpeted floors, may be reservoirs of viable and non-viable microorganisms and microbiological matter that elicit health symptoms. Prior research provides some support for this hypothesis, at least for an association between biological material on carpeting and symptoms. Dust mites, usually considered a problem in residences, have been found on surfaces in offices (Tharr 1991) and could be a source of symptoms in some individuals. In a Danish study of 14 town halls, the concentration of macromolecular organic dust of biological origin correlated strongly with the prevalences of mucosal and "general" symptoms (Gravesen, et al. 1990) and the authors reported finding a similar correlation from a study in schools. The weight of dust in vacuum cleaner samples (normalized by the floor surface area) and the quantity of high-surface-area materials, such as carpets and open shelves, were also correlated with symptom prevalence (Valbjorn and Skov 1987). In a follow-up study of four town halls, the quality of building cleaning and the quantity of high-surface-area materials were related to symptoms (Skov, et al., 1990). The presence of carpets also correlated to symptoms in a Swiss study (Norback and Torgen 1989) and in Phase 1 of the CHBS. In the Swiss study, symptoms decreased when carpets were removed. We suspect that these associations 
between symptom prevalence and carpeting could be related to biological contaminants, rather than to emissions of chemicals from carpets, because existing data indicate that the emission rates of chemicals declines rapidly (Hodgson, et al., 1992) and is probably insignificant after approximately six months or more after installation of the carpet. Because carpets have been associated with symptoms in newspaper articles, it is also possible that psychological factors contribute to the increased symptom prevalences among workers with carpets.

To the best of our knowledge, no previous research has been conducted on microbiological contamination on upholstered chairs. However, there are several reasons to suspect that microbiological contamination on these chairs is at least as important as contamination on floors. Chairs are infrequently cleaned. Occupants have extensive direct contact with the chairs. Hand contact with chairs followed by hand contact with the eyes or nose could be a route of exposure to microorganisms. The extensive human contact with chairs also increases the temperature and moisture content of the chair's surface, thus improving the conditions for survival or growth of microorganisms. Finally, the large expected number of skin flakes on chairs may result in a suitable environment for house dust mites (which feed on skin flakes). These reasons, together with the previously-described connection between symptoms and carpets, were considered adequate justification for research on the association between health symptoms and microbiological contamination on upholstered chairs.

\section{b. Objectives}

Our Phase 2 objectives were to evaluate measurement protocols for assessing the extent of biological contamination on both carpeted and hard-surface floors and on upholstered chairs. Specifically, we desired: (1) to evaluate a new quiet and unobtrusive technique for collecting samples from floors and chairs (see Appendix 6 of Fisk, et al., 1992); (2) to determine the spatial variability of culturable fungi and bacteria in surface dust samples taken at different locations on floors or on different chairs; (3) to compare the concentrations of microorganisms in samples collected on chairs and floors; and (4) to determine if dust mites were present in the office buildings.

\section{c. Methods}

\section{Sampling Procedures}

For this study, we used a new apparatus for collecting dust samples from surfaces. Dust samples were extracted from the floor or chair surface by drawing air with a pump into a metal sample tube with the open end of the tube slightly below the surface of the carpet or chair or slightly above a hard surface floor. The high velocity air entering the open end of the sample tube captured and transported dust particles and associated bioaerosols. The sample was drawn through a polycarbonate membrane filter with $0.4 \mu \mathrm{m}$ pores using a convenient and quiet battery-powered personal sampling pump. The sample flow rate 
was $4 \mathrm{lpm}$ and the internal diameter of the tube was $0.46 \mathrm{~cm}$, yielding a velocity of $4 \mathrm{~m} / \mathrm{s}$ at the inlet of the tube.

For sampling from floors, the sampling apparatus (described only in general terms here), included a slotted metal plate with three parallel $0.3 \mathrm{~m}$ long slots through the plate. The plate was placed on the floor. A metal disk held the sample tube and slid across the top of the plate with the sample tube extending through a slot (e.g., extending to the surface of the carpet). This apparatus precisely controlled the location of the open end of the sample tube relative to the surface of the floor, resulting in a more repeatable sampling process. The surface area from which dust was collected was not precisely known; therefore, the microbiological results (e.g., number of fungi) were normalized by the total length of the path sampled. To collect samples near an individual worker, we sampled from approximately 7 linear meters of floor surface, all within a $3 \mathrm{~m}$ distance of the worker's chair. The tube was drawn through the slots in both directions, thus each length of floor surface was sampled twice. By moving the slotted plate to different locations spaced approximately evenly throughout the floor surface of the study space, spatially integrated (called "space-wide") samples were collected based on a total sample length of $30 \mathrm{~m}$.

A very similar procedure and apparatus was used to collect dust samples from chairs. However, the flat slotted plate could not be placed directly on the curved surfaces of chairs, thus location of the tube's open end relative to the chair surface was manually controlled. The path length sampled from chairs was approximately $2.5 \mathrm{~m}$.

For analyses of dust mite concentrations, larger quantities of dust were required. (At least $0.05 \mathrm{~g}$ samples were desired for the microscopic sample analyses.) After gaining experience with sample collection for dust mite analyses, the path lengths of floor surface sampled near individual workers was increased to $14 \mathrm{~m}$ and the path length of chair surfaces sampled was increased to $7.5 \mathrm{~m}$. In addition, the tube was drawn through the slots in both directions twice, thus each meter of floor surface was sampled four times.

To provide information on measurement precision, replicate samples were collected from selected chairs and sections of the floor. Replicate samples were collected at locations near to, but not overlapping, the original samples.

\section{Sample Analysis Procedures}

To determine concentrations of culturable fungi in the floor- and chair-dust samples, we used the same procedure described above (see Hypothesis 1, Subhypothesis 2) and in Fisk, et al. (1992). Very similar sample analyses procedures were employed to determine concentrations of culturable bacteria in the dust samples except the culture medium was tryptic soy agar and two incubation temperatures were employed $\left(30^{\circ} \mathrm{C}\right.$ for mesophilic bacteria and 50 to $55^{\circ} \mathrm{C}$ for thermophilic bacteria). The fungal and bacterial colonies that grew on the culture media were classified as described in Appendix 5 of Fisk, et al. (1992). 
To determine concentrations of house dust mites, dust samples were inspected microscopically to determine the number of mites, the species (Dermatophagoides farinae or Dermatophagoides pteronyssinus), and the growth stage (e.g., mature, nymph, larval).

\section{d. Results}

\section{Total Fungi and Bacteria}

Table 4 provides the measured concentrations of total fungi and bacteria in colony forming units (cfu) per unit length of surface sampled. Because the sample lengths were only a few meters (except the space-wide samples were based on a $30 \mathrm{~m}$ length), concentrations below one cfu/m indicate that only a few colonies developed on the culture media. In these cases, the relative uncertainty in the measured concentrations is very high.

In a few samples from chairs in Building 2, fungi and bacteria concentrations are particularly high. However, second samples collected from the same chairs were lower by a factor of 10 to 50 . These data indicate a very high degree of spatial variability, even on a single chair. Even where replicate measurements of fungal or bacterial concentrations were more similar, the concentrations of two samples collected from the same chair or region of the floor frequently differed by more than a factor of three, again indicating a high degree of variability within a single chair or small surface of the floor.

Based on the small number of colonies of fungi or bacteria that developed in many samples and the large differences between concentrations in duplicate samples, we conclude that the new sampling technique, while convenient and non-obtrusive, does not meet our needs for future studies. A technique that samples from much larger surface areas, for example entire chairs or the entire floor in a workstation, should be employed to improve measurement precision and sample representativeness.

A few trends in the data are notable. The MEA culture medium resulted in substantially higher concentrations of fungi (mean $=77 \mathrm{cfu} / \mathrm{m}$ ) compared to the MEA-NACL culture medium (mean $=1.9 \mathrm{cfu} / \mathrm{m}$ ). The significance of the difference between the means was confirmed at using a non-parametric two-sided Wilcoxon Signed Rank Test. (The null hypothesis that the mean fungi concentration based on the MEA-NACL culture media was equal to the mean fungi concentration based on the MEA culture media was rejected at $\alpha=0.01$.) If two unusually high fungi concentrations from the MEA media are omitted, along with the paired fungi concentrations in the MEA-NACL medium, the means are $5.6 \mathrm{cfu} / \mathrm{m}$ for MEA and $0.6 \mathrm{cfu} / \mathrm{m}$ for MEA-NACL medium. The difference between the means remains significant at $\alpha=0.01$. This comparison is not intended as a rating of the relative usefulness of the two culture media. It simply suggest that the mean concentration of fungi that developed colonies on the MEA media significantly exceeded the mean concentration of fungi that developed colonies on the MEA-NACL media. 
Another trend is that the lower incubation temperature used for culturing mesophilic bacteria (closer to room and human body temperature) resulted in significantly higher concentrations of bacteria than the higher temperature incubation for thermophilic bacteria ( $\alpha=0.01$, two-sided Wilcoxon Signed Rank Test). The mean concentrations were $123 \mathrm{cfu} / \mathrm{m}$ at the $30^{\circ} \mathrm{C}$ incubation temperature compared to $1.6 \mathrm{cfu} / \mathrm{m}$ at the $50^{\circ} \mathrm{C}$ incubation temperature. Excluding the one unusually high concentration at $30^{\circ} \mathrm{C}$ and the paired concentration incubated at $50^{\circ} \mathrm{C}$, the means are $35 \mathrm{cfu} / \mathrm{m}$ at $30^{\circ} \mathrm{C}$ and $1.0 \mathrm{cfu} / \mathrm{m}$ at $50^{\circ} \mathrm{C}$. The concentration at $30^{\circ} \mathrm{C}$ remains significantly higher $(\alpha=0.01)$. This comparison is not an indication of the relative usefulness of the two incubation temperatures. The comparison is an indication of the relative abundance of bacteria that are able to develop colonies at the different incubation temperatures.

The mean concentrations of fungi and bacteria on chairs were higher than the mean concentrations on floors, but the differences in the means were not statistically significant. For fungal samples incubated on the MEA medium, the mean concentrations are $9.1 \mathrm{cfu} / \mathrm{m}$ for chair samples (excluding the two extreme high concentrations on chairs) and $2.9 \mathrm{cfu} / \mathrm{m}$ for floor samples; however, the two means are not significantly different based on a non-parametric two-sided Wilcoxon Two-Sample Test for Independent Samples with $\alpha=0.05$. For bacteria samples incubated at $30^{\circ} \mathrm{C}$, the mean concentrations are $44 \mathrm{cfu} / \mathrm{m}$ for chair samples (excluding the one extreme high concentration on a chair) and $27 \mathrm{cfu} / \mathrm{m}$ for floor samples (not significantly different at $\alpha=0.05$ ).

Our data suggest that concentrations of fungi and bacteria on upholstered chairs exceeded concentrations on floors (eight of twelve floor samples were from carpeted floors); however, the difference between the mean concentrations are not statistically significant. Because not all fungi and bacteria are likely to cause health effects, the actual importance of contamination of different surfaces (chairs versus floors) with respect to health cannot be determined solely by measurements of the concentrations on these surfaces. Chairs have been largely neglected in previous research on indoor microorganisms on surfaces. Chair surfaces should probably receive greater attention in the future. More protocol development will be needed.

\section{Dust Mites}

A total of 27 samples from chairs and floors in three different buildings were analyzed microscopically for dust mites. Four samples contained a single dust mite and one sample contained two mites plus one egg. The mites were of both species and included both the mature and nymph stages. Mites were present in two out of three buildings. Consequently, we did confirm the presence of mites in these buildings but the quantities seem to be low.

Initially the dust samples contained less that the minimum recommended quantity of dust $(0.05 \mathrm{~g})$ despite obtaining much larger quantities in pilot tests. Modifying the sampling protocol as described previously resulted in adequate size samples from the single 
building where the revised protocol was employed. The amount of dust collected varied considerably among buildings, possibly because of variations in cleaning practices between buildings.

Based on the small number of dust mites collected, future research should rely on samples from larger surface areas, as discussed above for measurement of fungi and bacteria on surfaces. In addition, the quantity of dust examined microscopically would need to be increased substantially to obtain useful data on dust mite counts. Because dust mite populations can vary seasonally, additional research during other seasons would also be valuable.

Table 4 Results of measurements of fungi and bacteria in dust samples collected from chairs and floors. Results of replicate measurements, i.e., pairs of samples collected from the same chair or region of the floor, are separated by commas.

\begin{tabular}{|c|c|c|c|c|c|c|}
\hline $\begin{array}{c}\text { Building } \\
\#\end{array}$ & $\begin{array}{c}\text { Sample } \\
\text { Type }\end{array}$ & Site ID & $\begin{array}{c}\text { Fungi MEA } \\
\text { (total cfu/m) }\end{array}$ & $\begin{array}{c}\text { Fungi } \\
\text { MEA-NACL } \\
\text { total cfu/m) }\end{array}$ & $\begin{array}{c}\text { Bacteria } \\
30^{\circ} \mathrm{C} \\
\text { (total cfu/m) }\end{array}$ & $\begin{array}{c}\text { Bacteria } \\
50^{\circ} \mathrm{C} \\
\text { (total cfu/m) }\end{array}$ \\
\hline 2 & chair & 1 & $5.7,980$ & 0,0 & $100,9.7$ & $1.6,0.8$ \\
\hline 2 & chair & 2 & 1600,33 & 46,0 & 3200,65 & 24,0 \\
\hline 2 & chair & 3 & 27 & 0 & 54 & 17 \\
\hline 2 & hard floor & 1 & $1.8,0.6$ & $0.6,0.3$ & $8.5,6.1$ & 0,0 \\
\hline 2 & hard floor & 2 & 3.2 & 0 & 26 & 0 \\
\hline 2 & hard floor & 3 & 0.3 & 0 & 12 & 0 \\
\hline 2 & hard floor & space wide & $4.1,0.9$ & $0.1,0.5$ & $8.9,25$ & $0,0.1$ \\
\hline 3 & chair & 1 & 11 & 0.8 & 24 & 0.8 \\
\hline 3 & chair & 2 & 0 & 0.8 & 13 & 4.8 \\
\hline 3 & chair & 3 & $2.4,0,1.6$ & $0.8,0.8,0.8$ & $60,51,36$ & $0.8,0.8,0$ \\
\hline 3 & chair & 4 & $0.8,4.0$ & $0.8,0.8$ & 53,32 & 0,0 \\
\hline 3 & carpet & 1 & $4.7,2.6$ & $0.6,0.6$ & 10,22 & $0.3,0.3$ \\
\hline 3 & carpet & 2 & 0.9 & 0.3 & 19 & 0.6 \\
\hline 3 & carpet & 3 & $6.1,8.2$ & $0.3,0.3$ & 82,82 & $0.3,1.7$ \\
\hline 3 & carpet & space wide & $2.1,4.5$ & $0.4,0.4$ & 29,21 & $0.7,0.4$ \\
\hline 4 & chair & 1 & $18,4.0$ & $6.5,0$ & 61,66 & $0.8,0$ \\
\hline 4 & chair & 2 & $13,5.7$ & $1.6,0.8$ & $65,7.3$ & $0.8,0$ \\
\hline 4 & chair & 3 & 10 & 0 & 12 & 0 \\
\hline 4 & carpet & 1 & $2.9,6.4$ & $0.3,0.6$ & 24,37 & $0.3,0.9$ \\
\hline 4 & carpet & 2 & 1.2 & 0.9 & 61 & 0.3 \\
\hline 4 & carpet & 3 & 2.6 & 0 & 8.2 & 0 \\
\hline 4 & carpet & space wide & $0.5,1.7$ & $0.5,0.6$ & $12.6,12.8$ & $0.4,0$ \\
\hline
\end{tabular}




\subsection{Hypothesis 2, Sub-hypothesis 2: The surface area of carpet per unit volume of indoor air correlates positively with occupant symptom prevalence.}

\section{a. Background}

The presence of carpet has been associated with office worker symptoms in European studies (Skov, et al., 1987, Norback and Torgen 1989) and in Phase 1 of the CHBS, presumably due to exposures to as-yet-unidentified contaminants. These contaminants could include physical or chemical components of the carpet, physical, chemical, or biological contaminants held by the carpet and re-released, biological contaminants amplified in the carpet, or chemicals added during carpet-cleaning procedures. The association between office worker symptoms and presence of carpet found in the European studies and in Phase 1 of this study has not been confirmed by other studies in the U.S.

One of the European studies (Skov, et al., 1987) did not assess symptom associations with carpets specifically, but assessed symptoms associated with total square feet of fabric surfaces (carpets, fabric-covered walls, seat covers, etc.) per volume of the office. They reported that this measure was associated with increased work-related symptoms. The other European study (Norback and Torgen 1989) found workers in buildings without carpet to have lower prevalences of symptoms than those in buildings with carpet, and also found that symptom prevalences decreased in one building after carpet was removed.

Assessment of carpets in Phase 1 of this study involved the determination, by inspection, of whether each respondent's workstation was within 15 feet of carpeting. As carpetrelated exposures might occur not at an individual level but at a space level, an additional variable was constructed from the individual variable, reflecting the proportion of respondents in each study space whose workstations were near carpet. The space-level carpet variable was associated with increases in a number of work-related symptoms, but the individual carpet measure was not. On the other hand, symptom prevalences in Phase 1 workers were slightly reduced among those in spaces with fabric partitions, although these fabric partitions were not common in our study. In Phase 2, we desired to gather more accurate quantitative information on carpets in the study spaces to check our initial findings. (Partitions in our study spaces were not common enough to warrant restudy.)

\section{b. Objectives}

The objectives of the phase 2 activities related to this hypothesis were to quantify the amount of carpet within each study space, the age of the carpet, and whether the carpet was installed using an adhesive, in order to allow an improved assessment of correlations with worker symptoms. 


\section{c. Methods}

Information on carpets was collected by inspection of the study spaces and through interviews of appropriate building personnel. As one goal was to estimate the amount of carpet at the time of the Phase 1 questionnaire, any changes in carpeting since then were determined in interviews with appropriate building personnel. Findings were recorded on the forms provided in Appendix 7 of Fisk, et al. (1992).

\section{d. Results}

Table 5 lists the total carpet area in each study space that contains carpet as well as the ratio of carpet area to indoor volume during the Phase-1 study. Carpet age and adhesive use are also tabulated. These data will be used in bivariate and adjusted analyses to determine the associations to symptom prevalences during Phase 1 .

Table 5. Results of assessment of carpet area.

\begin{tabular}{|c|c|c|c|c|c|}
\hline $\begin{array}{c}\text { SPACE } \\
\text { NUMBER } \\
*\end{array}$ & $\begin{array}{c}\text { TOTAL } \\
\text { AREA OF } \\
\text { CARPET } \\
\text { IN PHASE } \\
2\left(\mathrm{~m}^{2}\right)\end{array}$ & $\begin{array}{c}\text { TOTAL } \\
\text { AREA OF } \\
\text { CARPET } \\
\text { IN PHASE } \\
1\left(\mathrm{~m}^{2}\right)\end{array}$ & $\begin{array}{c}\text { PHASE 1 CARPET } \\
\text { AREA PER UNIT } \\
\text { INDOOR VOLUME } \\
\left(\mathrm{m}^{-1}\right)\end{array}$ & $\begin{array}{c}\text { AGE OF CARPET } \\
\text { DURING PHASE } 1 \\
\text { (years) }\end{array}$ & $\begin{array}{c}\text { CARPET } \\
\text { INSTALLED WITH } \\
\text { ADHESIVE }\end{array}$ \\
\hline 31 & 610 & 610 & 0.36 & 6 & Yes \\
\hline 32 & 770 & 770 & 0.36 & 6 & Yes \\
\hline 33 & 1500 & 1500 & 0.36 & 6 & Yes \\
\hline 41 & 650 & 650 & 0.39 & 1.5 & Yes \\
\hline 42 & 650 & 650 & 0.39 & 2 & Yes \\
\hline 43 & 650 & 650 & 0.34 & 1 & Yes \\
\hline 44 & 47 & 47 & 0.39 & 1 & Yes \\
\hline$\overline{51}$ & 470 & 470 & 0.33 & 12 & Yes \\
\hline 52 & 470 & 470 & 0.33 & 12 & Yes \\
\hline 53 & 68 & 68 & 0.05 & 12 & Yes \\
\hline 61 & 700 & 0 & 0 & -- & -- \\
\hline 81 & 103 & 103 & 0.04 & 10 & Yes \\
\hline 82 & 89 & 63 & 0.03 & 10 & Yes \\
\hline 91 & 130 & 130 & 0.328 & 10 & Yes \\
\hline 102 & 32 & 32 & 0.13 & $4 ?$ & No \\
\hline 103 & 33 & 33 & 0.03 & 7.5 & No \\
\hline 104 & 100 & 100 & 0.22 & $\begin{array}{c}15(\text { Room } 315) \\
2(\text { Room } 304)\end{array}$ & No \\
\hline 111 & 100 & 100 & 0.01 & 13 & No \\
\hline
\end{tabular}

\footnotetext{
* In two (three) digit space numbers, the first digit (two digits) is the building number.
} 


\subsection{Hypothesis 2, Sub-hypothesis 3: The quality of office cleaning and the nature of office pest-control practices is associated with occupant symptom prevalence.}

\section{a. Background and Objectives}

Although evidence suggests that environmental contaminants may contribute to high symptom levels in offices, specific contaminants have not been strongly and consistently associated with symptoms. General environmental indicators, if found to be associated with worker symptoms, would help target more specific exposures. Office cleaning practices may affect levels of certain indoor contaminants, and thus indirectly affect exposures.

An association of symptom increases with poor office cleaning practices has been reported from a follow-up study to the Danish Town Hall study (Skov, et al., 1990). The initial study of 14 buildings found no association between symptoms and a cleaning index, in either unadjusted or multivariate adjusted analyses (Skov, et al., 1987). However, the follow-up study of two high and two low symptom buildings found a possible association of mucosal irritation symptoms with quality of cleaning (Skov, et al., 1990).

The follow-up study to the Danish Town Hall involved a "semi-quantitative estimation of the quality of cleaning according to cleaning methods, materials, frequency, and ability of carrying through the cleaning," in 8-10 offices in each of the four buildings. It is implied that this same procedure was used in the initial study, and it is not clear why findings should have differed between the two studies.

\section{b. Objectives}

The objective of our Phase-2 activities were to identify aspects of cleaning practices which might possibly correlate with worker symptom reports. These relationships might be due to insufficient removal of particular contaminants, or addition of chemical compounds (for cleaning, disinfection, or pest control) into the indoor environment.

\section{c. Methods}

The assessment of office cleaning practices ascertained types of cleaning procedures and materials used, schedules for those procedures, records of past performance, and evidence of past performance. In addition, schedules of pesticide use and the specific substances used were determined. Information was collected by interviews with appropriate personnel (from building management or maintenance staff, or outside contractors), and by inspection of indoor spaces. Information gathered included: methods and frequency of cleaning floor surfaces (both hard-surfaced and with carpets) and other furniture or interior surfaces; description, frequency, and methods of using chemical cleaners, rug 
shampoos, or disinfectants. Any changes in practices, or in cleaning contractors, between the Phase 1 and Phase 2 study periods were also assessed. Findings were recorded on the forms illustrated in Appendix 8 of Fisk, et al. (1992).

\section{d. Results}

A number of the variables showed sufficient variation among the buildings to use in analyses, to see if improved cleaning of specific types, or combined in a composite index, is associated with decreased symptom prevalence. These variables include: presence of written cleaning schedule; frequency of carpet vacuuming, frequency of hard floor waxing, frequency of cloth furniture dusting/vacuuming; and frequency of hard surface dusting/vacuuming. The responses to the space cleaning assessment are summarized in Table 6.

Table 6. Results of space cleaning assessment. Buildings with identical cleaning practices are listed in the same column.

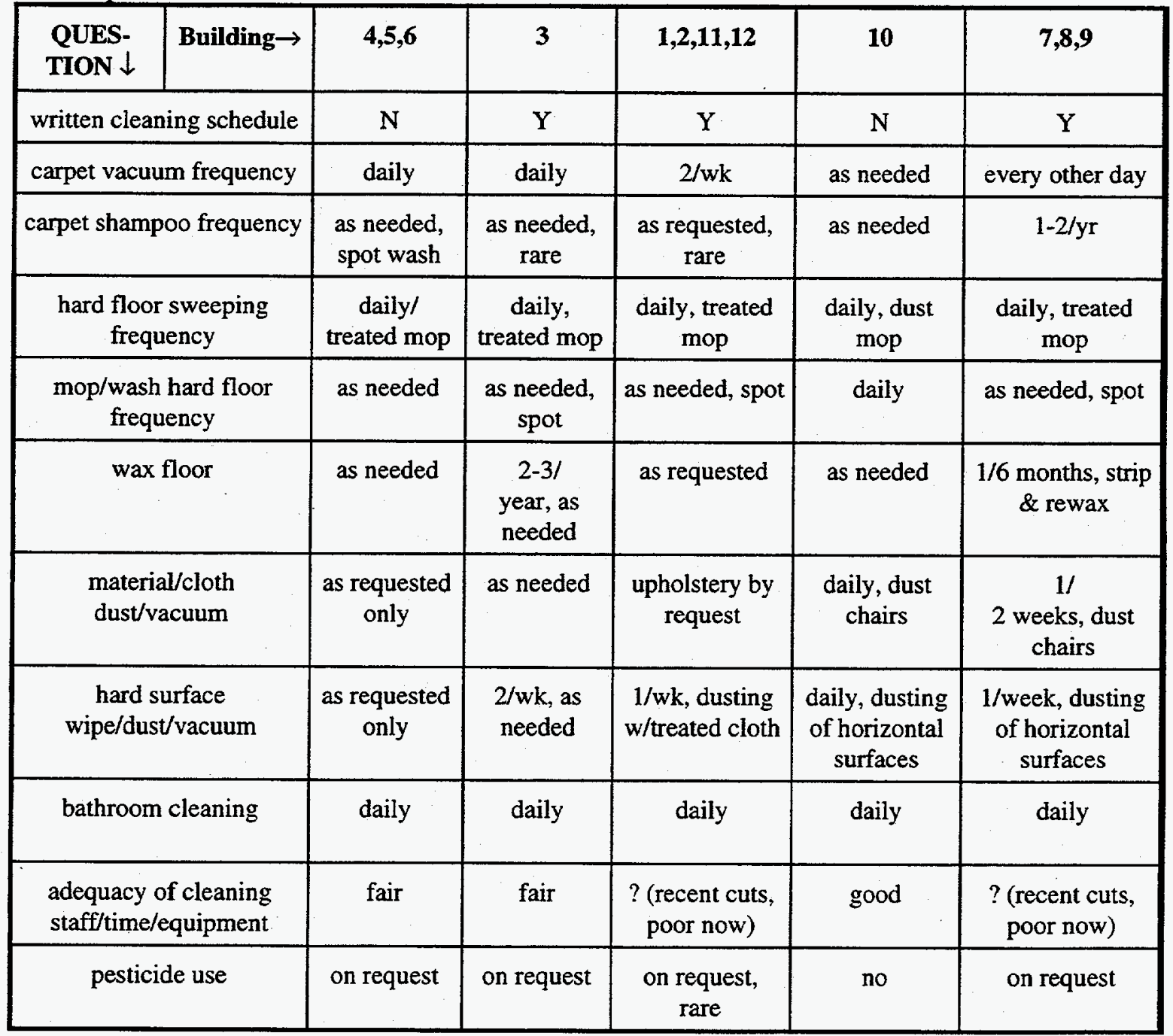




\section{Hypothesis No. 8: Increased sound is correlated with increased symptom prevalence.}

\section{a. Background}

In the Danish Town Hall Study, sound levels were measured but, to the best of our knowledge, no results have been published. Sundell (1991) found a correlation between occupants' subjective sensations of noise and many symptoms. He did not measure sound levels. Hodgson, et al. (1991) measured sound levels in a survey of five building areas and 147 occupants. They reported no correlation between sound levels and symptoms. In the CHBS Phase 1 questionnaire, occupants were asked, "At your present workstation, how often were you bothered by noise?" It has yet to be determined whether responses to this question are correlated to any symptoms in Phase 1.

Many studies have evaluated the physiological effects due to sound from automobiles, aircraft, and industrial machines. Specific effects that have been found in high sound environments include: loss of hearing, headache, high blood pressure, fatigue, and nausea. More generally, sound can be an annoyance or a cause of stress, both of which may cause symptoms. There is a need to determine if there is a threshold sound level for noise to correlate with symptoms.

The measurement of sound level is relatively easy and inexpensive; however, the interpretation of noise is not a straight-forward task. Besides the obvious $\mathrm{dB}$ scale for measuring the sound pressure level, there are other qualities of sound which should be taken into account. Sound experts suggest that high frequency sound is associated with occupants feeling tense and anxious, whereas low frequency sound is associated with headaches. The extent to which sound is annoying may depend on whether the sound is constant or intermittent and the type of source, e.g., the human voice, typewriter keys or fan noise from the ventilation system. Unfortunately, there are no standard methods for assessing these characteristics of sound.

There are instruments which will measure the sound pressure level adjusted for the response of the ear. This A-weighting sound pressure level has the advantage of providing a number that correlates well with human judgment of relative loudness, but it does not correlate well with human judgment of the subjective quality of the sound. Other scales to measure sound have been designed but no instrument can judge the quality of sound nearly as well as the human ear.

\section{b. Objectives}

The objective of the Phase 2 investigation was to investigate the spatial and temporal variations in sound levels within study areas so that a protocol for sound-level measurements could be designed and used in a Phase 3 study. 


\section{c. Methods}

Measurements were made with a B\&K model 2230 sound level meter which collects two channels of data. Random incidence microphones were mounted at the height of an occupant's ear on a tripod and oriented at a $45^{\circ}$ angle relative to the planes of the walls and floor. This orientation reduces the amount of reflected noise that is measured. In most spaces, the microphones were separated by a distance of approximately $2.5 \mathrm{~m}$. Sound pressure level was measured on the $\mathrm{dB}(\mathrm{A})$ and $\mathrm{dB}(\mathrm{C})$ scales and the difference between the two values calculated to determine whether the noise is predominantly high or low frequency. (The $\mathrm{db}(\mathrm{C})$ scale gives greater weight to low frequency sounds.)

Sound pressure levels were measured in 14 study spaces. At three times during a single day(mid morning, early afternoon, and late afternoon), a sequence of two five-minutelong measurements were completed at four-to-six sites in each study space. The measurement sites were spaced approximately evenly throughout the study space.

\section{d. Results}

Table 7 summarizes the results of the sound pressure level measurements. In reviewing these data, one must keep in mind the logarithmic nature of the decibel unit (e.g., arithmetic averages of values are inappropriate). Most of the tabulated data pertain to the $\mathrm{db}(\mathrm{A})$ scale. The sound data from individual study spaces tended to be approximately normally distributed. The spatial and temporal standard deviations in the sound pressure levels were similar in magnitude and almost always less than one tenth of the mean measured sound pressure levels. Based on Figure 1, which shows the $95 \%$ confidence limits in the $d b(A)$ levels within each study space (data from both microphone channels have been combined), the monitoring protocol was adequate to distinguish between many study spaces based on their mean sound pressure level (i.e., not all sets of confidence limits overlap). Consequently, the monitoring protocol yields mean values of sound pressure level that adequately integrate the temporally- and spatially variable data within study spaces. Increasing the number of measurement locations and times would better define the occupant's exposure to noise but is not essential to obtain useable data.

The sound pressure levels in the $\mathrm{db}(\mathrm{C})$ and $\mathrm{db}(\mathrm{A})$ scales are not well correlated $\left(\mathrm{r}^{2}=0.11\right)$, thus, one number is not an accurate surrogate for the other. Therefore, measurements to characterize the sound pressure level on each scale are appropriate. 
Table 7. Results of measurements of sound pressure levels.

\begin{tabular}{|c|c|c|c|c|c|c|c|c|}
\hline Space \# & $\begin{array}{c}\text { Temporal } \\
\text { Standard } \\
\text { Deviation } \\
\mathrm{db}(\mathrm{A})\end{array}$ & $\begin{array}{c}\text { Spatial } \\
\text { Standard } \\
\text { Deviation } \\
\mathrm{db}(\mathrm{A}) \\
\text { Channel A }\end{array}$ & $\begin{array}{c}\text { Spatial } \\
\text { Standard } \\
\text { Deviation } \\
\mathrm{db}(\mathrm{A}) \\
\text { Channel B }\end{array}$ & $\begin{array}{c}\text { Mean } \\
\mathrm{db}(\mathrm{A}) \\
\text { Channel A }\end{array}$ & $\begin{array}{c}\text { Mean } \\
\mathrm{db}(\mathrm{A}) \\
\text { Channel B B }\end{array}$ & $\begin{array}{c}\text { Mean } \\
\mathrm{db}(\mathrm{C})- \\
\text { Mean } \\
\mathrm{db}(\mathrm{A}) \\
\text { Channel A }\end{array}$ & $\begin{array}{c}\text { Mean } \\
\mathrm{db}(\mathrm{C})- \\
\text { Mean } \\
\mathrm{db}(\mathrm{A}) \\
\text { Channel B }\end{array}$ & Notes \\
\hline 11 & 4.5 & 4.3 & & 58.7 & & 11.2 & & 1 \\
\hline 21 & 3.1 & 2.4 & 1.8 & 59.8 & 58.2 & 11.5 & 7.2 & 1 \\
\hline 32 & 3.6 & 5.1 & 4.7 & 54.5 & 55.2 & 15.8 & 16.6 & 2 \\
\hline 33 & 5.0 & 4.1 & 2.8 & 54.8 & 53.1 & 18.8 & 18.7 & 2 \\
\hline 42 & 4.7 & 2.3 & 1.8 & 52.6 & 53.0 & 13.2 & 12.8 & 2 \\
\hline 51 & 2.5 & 5.2 & 5.5 & 50.4 & 52.2 & 14.8 & 13.4 & 2 \\
\hline 61 & 2.5 & 2.1 & 0.9 & 57.3 & 56.0 & 6.2 & 6.6 & 2 \\
\hline 72 & 2.3 & 0.8 & 2.1 & 54.6 & 54.0 & 13.4 & 14.4 & 2 \\
\hline 82 & 2.6 & 3.1 & 3.0 & 56.6 & 56.7 & 15.0 & 15.7 & 2 \\
\hline 93 & 3.7 & 3.8 & 5.7 & 55.1 & 58.5 & 13.2 & 13.1 & 2 \\
\hline 102 & 2.9 & 2.6 & 2.5 & 56.1 & 56.2 & 8.5 & 8.3 & 1 \\
\hline 103 & 1.9 & 1.6 & 2.0 & 55.7 & 55.5 & 6.7 & 7.4 & 1 \\
\hline 111 & 2.2 & 0.8 & 1.6 & 54.9 & 55.8 & 7.8 & 7.6 & 1 \\
\hline 121 & 3.0 & 2.2 & 2.1 & 61.6 & 61.5 & 4.8 & 4.9 & 1 \\
\hline
\end{tabular}

Notes: 1. Channel A \& B microphones next to each other

2. Microphones apart

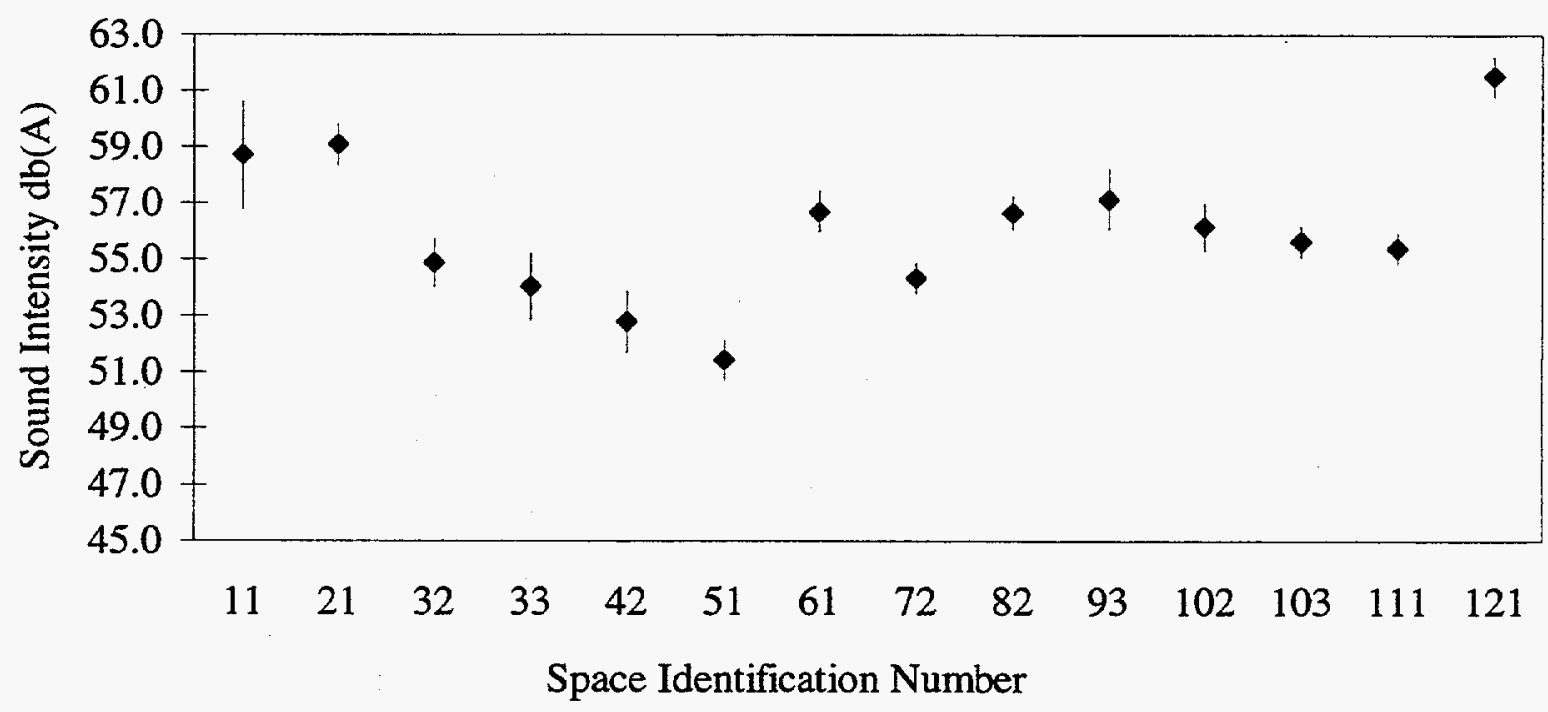

Figure 1. Mean noise levels and $95 \%$ confidence limits. 


\section{Hypothesis 9: Flicker from lighting is associated with the prevalence of headaches in office workers.}

\section{a. Background}

In office buildings, most of the indoor lighting is supplied by fluorescent lamps. The light emitted by the arc discharge in a fluorescent lamp is a function of the instantaneous power input and thus reflects cyclic changes in power input. The cyclic variation in energy output, which is twice the input frequency, is transferred to the emitted light output, with some dampening because of the persistence of the phosphors, and results in a variation in light output which is called "flicker." With a 60-hertz input frequency, the resulting 120 -hertz variation is too fast to be noticed by the eye, i.e., perceptual fusion occurs.

There is experimental evidence that components of the visual pathway respond synchronously to periodically oscillating light stimuli (flicker) at frequencies above perceptual fusion. Berman, et al. (1991), for example, have reported synchronous responses of the human retina to a fluorescent luminaire with controllable driving frequency at rates as high as $145 \mathrm{~Hz}$. There is also evidence that lighting flicker at 100 $\mathrm{Hz}$ can cause headaches. In a double-blind, crossover experiment, Wilkins, et al. (1988) compared two lighting situations: (1) fluorescent lamps with a solid state high frequency ballast giving illumination with $100 \mathrm{~Hz}$, with a peak modulation of less than seven percent and, (2) fluorescent lamps with standard ballasts which fluctuated with a peak modulation of 40 to 50 percent and a principal frequency component of $100 \mathrm{~Hz}$. The incidence of headaches and eye strain was reduced by half under high frequency lighting. In general, women appear to be more sensitive to lighting flicker than men and young people more sensitive than older people (Rubinstein 1992). Since headache symptoms have often been associated with sick building syndrome and the lighting flicker varies among buildings due to variations in lamp and ballast types, some investigation of office lighting characteristics is appropriate.

The percent flicker is the parameter used to characterize flicker. From the measured data, percent flicker was calculated as $100(\mathrm{~A}-\mathrm{B}) /(\mathrm{A}+\mathrm{B})$, where $\mathrm{A}$ and $\mathrm{B}$ are the heights of the maximum and the minimum illuminance, respectively, above the zero light baseline, of the wave for a single cycle (IES Lighting Handbook 1984).

\section{b. Objectives}

The objectives during Phase 2 were to measure percent lighting flicker in each study space, and the spatial variance in flicker, so the association between percent flicker and symptoms could be evaluated. To minimize errors from using Phase-2 lighting flicker data in conjunction with the prior Phase-1 symptom prevalences, a second objective was to identify spaces where lighting flicker had changed since Phase 1 due to changes in lighting equipment. 


\section{c. Methods}

Lighting flicker was measured in the all 12 office buildings and in 28 study spaces. An oscilliscope displayed the output signal of a fast-response photodiode connected to an amplifier. The photodiode was placed on a level surface at three-to-six locations in each space. The oscilloscope was adjusted to obtain the wave form and a Polaroid camera was used to photograph the wave on the oscilloscope screen.

The building maintenance and management staff were questioned regarding any changes in the ballasts or lamps for the fluorescent fixtures in the area since Summer, 1990.

\section{d. Results}

Table 8 gives the minimum, maximum, and mean values of percent flicker in each study space. The ratio of minimum to maximum percent flicker exceeds 2.0 in 19 of 28 spaces, consequently, the calculated mean flicker based on three to six (usually four or six) measurements is likely to only approximately represent the true spatial mean in some spaces. The mean percent flicker based on all measurements is $26 \%$ with a standard deviation of $13 \%$. We will assess the associations between mean percent flicker and prevalence of headache; however, we recognize that uncertainties in the mean percent flicker for each study space may obscure any true associations.

Much of the spatial variability in percent flicker within study spaces appeared to be a consequence of natural light, which predominantly affected locations near windows. Consequently, we have calculated the mean percent flicker in each study space based only on measurements performed at a distance of $4.6 \mathrm{~m}$ or greater from a window. These values and their range are illustrated in Figure 2. We also plan to evaluate associations between these percent flicker values and the prevalence of headaches in occupants located greater than $4.6 \mathrm{~m}$ from a window. (In the Phase 1 questionnaire, occupants were asked if their workstation was more than $4.6 \mathrm{~m}$ from a window.) 
Table 8. Results of lighting flicker measurements.

\begin{tabular}{|c|c|c|c|c|}
\hline Space \# & $\begin{array}{c}\text { NUMBER OF } \\
\text { MEASUREMENT } \\
\text { LOCATIONS }\end{array}$ & $\begin{array}{c}\text { MINIMUM \% } \\
\text { FLICKER }\end{array}$ & $\begin{array}{c}\text { MAXIMUM \% } \\
\text { FLICKER }\end{array}$ & $\begin{array}{c}\text { MEAN \% } \\
\text { FLICKER }\end{array}$ \\
\hline 11 & 4 & 12 & 26 & 19 \\
\hline 12 & 6 & 7 & 30 & 18 \\
\hline 21 & 6 & 3 & 14 & 11 \\
\hline 22 & 6 & 6 & 19 & 10 \\
\hline 31 & 4 & 34 & 42 & 38 \\
\hline 32 & 6 & 17 & 34 & 22 \\
\hline 33 & 6 & 21 & 43 & 30 \\
\hline 41 & 6 & 11 & 24 & 19 \\
\hline 42 & 6 & 13 & 23 & 20 \\
\hline 43 & 6 & 19 & 32 & 26 \\
\hline 51 & 4 & 23 & 33 & 29 \\
\hline 52 & 4 & 17 & 47 & 30 \\
\hline 53 & 4 & 19 & 35 & 26 \\
\hline 61 & 4 & 14 & 35 & 23 \\
\hline 71 & 4 & 23 & 33 & 27 \\
\hline 72 & 6 & 17 & 30 & 25 \\
\hline 81 & 6 & 1 & 52 & 33 \\
\hline 82 & 6 & 13 & 38 & 21 \\
\hline 91 & 4 & 27 & 29 & 28 \\
\hline 92 & 4 & 10 & 28 & 18 \\
\hline 93 & 4 & 5 & 30 & 15 \\
\hline 94 & 4 & 1 & 33 & 18 \\
\hline 101 & 3 & 15 & 100 & 48 \\
\hline 102 & 4 & 52 & 94 & 66 \\
\hline 103 & 4 & 24 & 60 & 40 \\
\hline 104 & 6 & 30 & 74 & 52 \\
\hline 111 & 6 & 8 & 17 & 11 \\
\hline 121 & 6 & 5 & 18 & 12 \\
\hline & & & & \\
\hline
\end{tabular}




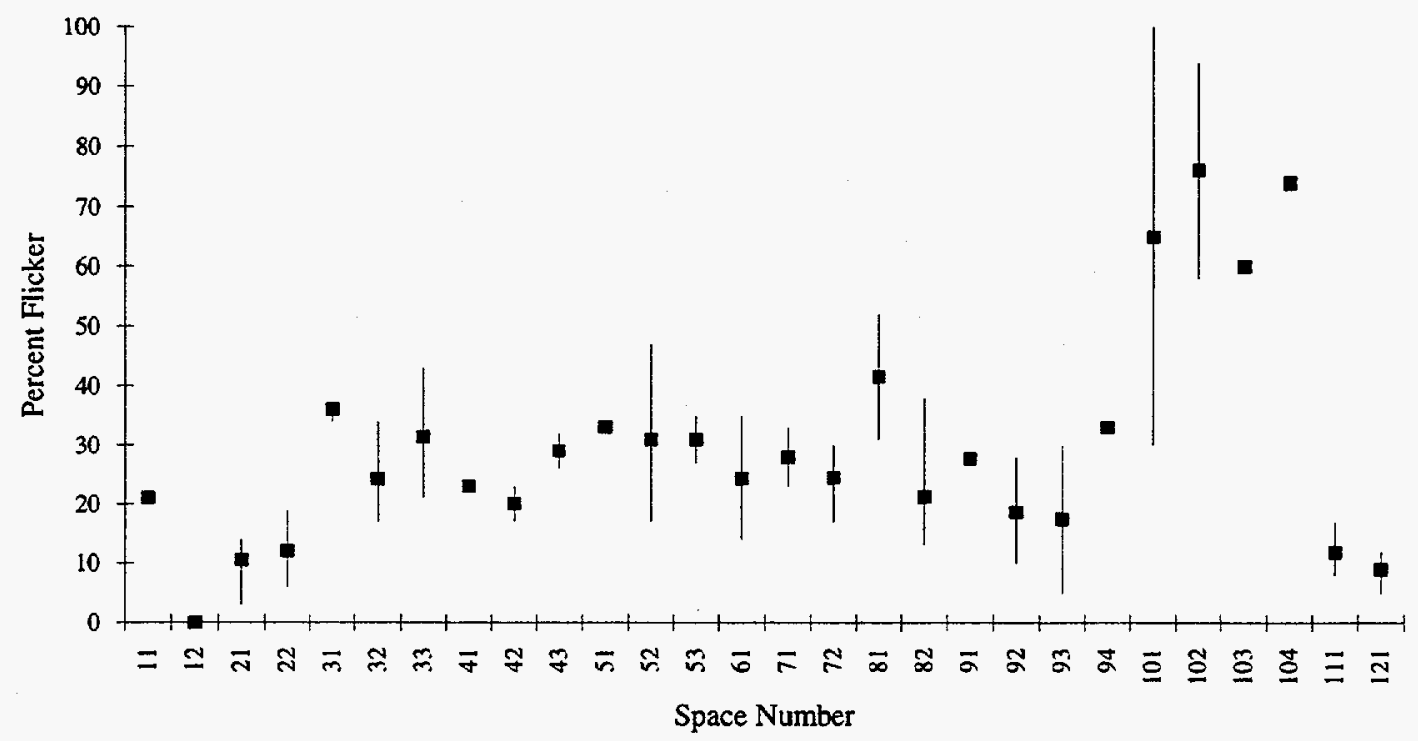

Figure 2: Mean values and total range of percent lighting flicker at measurement locations greater than 15 feet from a window.

\section{ACKNOWLEDGMENTS}

The authors thank Paul Jenson of NIOSH for assisting with development of the apparatus for collecting dust samples from floors, Mary Kay O'Rourke of the University of Arizona for analyses of the dust mite samples, John Franks of NIOSH for advice on noise measurements, Francis Rubinstein, Evan Pert and Oliver Morse for technical advice and assistance with instrumentation for lighting measurements. We also thank the operators and occupants of the study buildings for their assistance and cooperation throughout this study.

This research was supported by the Assistant Secretary for Energy Efficiency and Renewable Energy, Office of Building Technologies, Building Systems and Materials Division of the U.S. Department of Energy (DOE) under Contract No. DE-AC0376SF00098, and by the National Institute for Occupational Safety and Health of the U.S. Centers for Disease Control and Prevention. 


\section{REFERENCES}

Balaras, C.A., Santamouris, M., Dascalaki, E., Argiriou, A., Assimakopoulos, D., and Loizidou, M. (1993) Indoor air quality and health symptoms in town halls in Athens, Hellas. Proceedings of Indoor Air'93 The 6th International Conference on Indoor Air Quality and Climate, vol. 1, 315 - 320, July 4 - 8, 1993, Helsinki, Finland.

Berman, S. M., Greenhouse, D.S., Bailey, I.L., Clear, R.D., and Raasch, T.W. (1991) "Human Electroretinogram Responses to Video Displays, Fluorescent Lighting and other High Frequency Sources." Optometry and Vision Science 68, pp. 645-662.

Burge, H.A. (1990) "The Fungi," in Biological Contaminants in Indoor Environments, P.R. Morey, J.C. Feeley and J. A. Otten, Eds. American Society for Testing and Materials, Philadelphia, PA. pp. 136-162.

Burge, H.A., Feeley, J.C. Sr., Kreiss, K., Milton, D., Morey, P.R., Otten, J.A., Peterson, K., Tulis, J.J., and Tyndall, R. (1989) Guidelines for the Assessment of Bioaerosols in the Indoor Environment, American Conference of Governmental Industrial Hygienists, Cincinnati, $\mathrm{OH}$.

Burge, S., Hedge, A., Wilson, S., Bass, J.H., and Robertson, A. (1987) "Sick Building Syndrome: A Study of 4373 Office Workers." Ann. Occup. Hyg. 31(4A), pp. 493-504.

Burge, H. A. and Solomon, W.R. (1987) "Sampling and Analysis of Biological Aerosols," Atmos Env. 21(2), pp. 451-456.

Daisey, J.M., Fisk, W.J., Hodgson, A.T, Mendell, M.J., Faulkner, D., Nematollahi, M., and Macher, J.M. (1990) "The California Healthy Building Pilot Study I. Study Design and Protocol." Lawrence Berkeley Laboratory Report, LBL-29851, Berkeley, CA.

Elixmann, J.H., Schata, M., and Jorde W. 1990. "Fungi in Filters of Air Conditioning Systems Cause the Building Related Illness." Proceedings of the Fifth International Conference on Indoor Air Quality and Climate, Toronto, vol. 1, pp. 193-202. Published by the International Conference on Indoor Air Quality and Climate, Inc., 2344 Haddington Crescent, Ottawa, Ontario, K1H 8J4.

Fanger, P.O., Lauridsen, J., Bluyssen, P., and Clausen, G. (1988) "Air Pollution Sources in Offices and Ventilation Halls, Quantified by the Olf Unit." Energy and Buildings 12 , pp. $7-19$.

Fisk, W.J., Mendell, M. J., Daisey, J. M., Faulkner, D., Hodgson, A.T., Nematollahi, M., and Macher, J. (1993) "Phase 1 of The California Healthy Building Study: A Summary" Indoor Air 3(4), pp. 246-254.

Fisk, W.J., Hodgson, A.T., Macher, J.M., Mendell, M.J., Daisey, J.M., and Faulkner, D. (1992) "Hypothesis-Based Research on The Causes of Sick Building Symptoms: A Design for Phases 2 and 3 of the California Healthy Building Study." LBL-33434, Lawrence Berkeley Laboratory, Berkeley, CA.

Flannigan, B. (1992) "Approaches to assessment of the microbial flora of buildings", Presented at IAQ'92, Environments for People, October 18 - 21, San Francisco, CA (not included in the proceedings)

Gamboa, R.R., Gallagher, B.P., and Matthews, K.R. (1988) "Data on Fiber Contribution to the Supply Airstream from Fiberglass Duct Liner and Fiberglass Duct Board." In 
proceedings of IAQ'88, April 11-13, Atlanta, pp. 25 - 33. Published by ASHRAE, Atlanta, GA.

Gravesen, S., Skov, P., Valbjorn, O., and Lowenstein, H. (1990). "The Role of Potential Immunogenic Components of Dust (MOD) in the Sick Building Syndrome." Proceedings of the Fifth International Conference on Indoor Air Quality and Climate, Toronto, vol. 1, pp. 9 - 13. Published by the International Conference on Indoor Air Quality and Climate, Inc., 2344 Haddington Crescent, Ottawa, Ontario, K1H $8 \mathrm{~J} 4$.

Hedge, A., Erickson, W.A., and Rubin, G. (1993) Effects of man made mineral fibers in settled dust on sick building syndrome in air conditioned offices. Proceedings of Indoor Air'93 The 6th International Conference on Indoor Air Quality and Climate, vol. 1, $291-296$, July $4-8,1993$, Helsinki, Finland.

Hodgson, A.T., Wooley, J.D., and Daisey, J.M. (1992) "Volatile Organic Chemical

Emissions from Carpets." Lawrence Berkeley Laboratory Report, LBL-31916, Berkeley, CA 94720.

Hodgson, M.J., Frohliger, J., Permar, E., Tidwell, C., Traven, N.D., Olenchock, S.A., and

Karpf, M. (1991) "Symptoms and Microenvironmental Measures in Nonproblem Buildings." Journal of Occupational Medicine 33 (4), pp. 527 - 533.

Hood, M. A. (1990) "Gram Negative Bacteria as Bioaerosols," in Biological Contaminants in Indoor Environments, P. R. Morey, J. C. Feeley and J. A. Otten, Eds. American Society for Testing and Materials, Philadelphia, PA, pp. 60-70.

IES Lighting Handbook. Reference Volume. (1984) J.E. Kaufman and J.F. Christensen, Eds., Illuminating Engineering Society of North America, New York, New York.

Jaakkola, J. J.K., Miettinen, P., Tuomaala, P., and Seppanen, O. (1993) The Helsinki Office Environment Study: the type of ventilation system and the sick building syndrome. Proceedings of Indoor Air'93 The 6th International Conference on Indoor Air Quality and Climate, vol. 1, 285 - 290, July 4 - 8, 1993, Helsinki, Finland.

Martikainen, P.J., Asikainer, A., Nevabiner, A., Jantunen, M., Pasanen, P., and Kalliokski, P. (1990) "Microbial Growth on Ventilation Filter Materials" Proceedings of the Fifth International Conference on Indoor Air Quality and Climate, Toronto, vol. 3, pp. 203 - 206. Published by the International Conference on Indoor Air Quality and Climate, Inc., 2344 Haddington Crescent, Ottawa, Ontario, K1H 8J4.

Mendell, M. (1991) "Health Effects in Office Workers Associated with Ventilation Systems: Evidence from the First U.S. Study." Doctoral Dissertation, University of California at Berkeley, Program in Epidemiology, Berkeley, CA, October, 1991.

Mendell, M.J. and Smith, A.H. (1990) "Consistent Pattern of Elevated Symptoms in Air Conditioned Office Buildings: A Reanalysis of Epidemiologic Studies." Am. J. Public Health 80 (10), pp. 1193-1199.

Mendell, M.J., Fisk, W.J., Smith, A.H., Seavey, W., Hodgson, A.T., Daisey, J.M., Smith, D.F., Macher, J.M., and Goldman, L. (1993) "Elevated Symptom Prevalence Associated with Mechanical Ventilation in Office Buildings: Findings from the California Healthy Building Study, Phase 1," Lawrence Berkeley Laboratory Report, LBL-33569, Berkeley, CA.

Molhave, $L$ and M. Thorsen (1991) "A Model for Investigations of Ventilation Systems as Sources for Volatile Organic Compounds in Indoor Climate." Atmospheric Environment 25, pp. 241-249. 
Morey, P.R. and Williams, C.M. (1991) "Is Porous Insulation Inside an HVAC System Compatible with a Healthy Building?" Proceedings of IAQ'91: Healthy Buildings, pp. 128 - 135. Published by ASHRAE, Atlanta, GA.

Morey, P.R., Feeley, J.C., and Otten, J.A. Eds. (1990) Biological Contaminants in Indoor Environments. American Society for Testing and Materials, Philadelphia, PA.

Norback, D. and Torgen, M. (1989) "A Longitudinal Study Relating Carpeting with Sick Building Syndrome." Environ. Int. 15, pp. 129-135.

Rubinstein, F. (1992) lighting researcher at Lawrence Berkeley Laboratory, personal communication.

Schneider, T., Nielsen, O., Bredsdorff, P., and Linde, P. (1990) "Dust in Buildings with Man-Made Mineral Fiber Ceiling Boards." Scand. J. Environ. Health 16, pp. 434-439.

Shumate, M.W., and Wilhelm, J.E. (1991) "Air Filtration Media -- Evaluations of Fiber Shedding Characteristics Under Laboratory Conditions and in Commercial Installations." In proceedings of IAQ'91, pp. 337-341, Published by ASHRAE, Atlanta, GA.

Skov, P., Valbjorn, O. and DISG (1987) "The Sick Building Syndrome in the Office Environment: The Danish Town Hall Study." Environ. Int. 13, pp. 339-349.

Skov, P., Valbjorn, O., and DISG: (1990) The Danish Town Hall Study -- A One-Year Followup." Proceedings of the Fifth International Conference on Indoor Air Quality and Climate, Toronto, vol 1, pp. 787 791. Published by the International Conference on Indoor Air Quality and Climate, Inc., 2344 Haddington Crescent, Ottawa, Ontario, $\mathrm{K} 1 \mathrm{H} 8 \mathrm{~J} 4$.

Sundell, J., Andersson, B., Andersson, K., and Lindvall, T. (1993) Volatile organic compounds in ventilation air in buildings at different sampling points in the buildings and their relationship with the prevalence of occupant symptoms. Indoor Air 3(2), pp. 82-93.

Sundell, J., Lindvall, T., Stenberg, B. (1991) "Influence of Type of Ventilation and Outdoor Airflow Rate on the Prevalence of SBS Symptoms." In Proceedings of IAQ '91 Healthy Buildings, pp. $85-89$, September $4-8$, Washington, D.C. Published by ASHRAE, Atlanta, GA.

Tharr, D. (1991) "House Dust Mite Allergy in an Office Building." Appl. Occup. Environ. Hyg. 6 (2), pp. 94 - 96.

Valbjorn, O. and Skov, P. (1987) "Influence of Indoor Climate on the Sick Building Syndrome Prevalence." Proceedings of Indoor Air'87, vol. 2, pp. 593-597. Printed by Oraniendruck GmbH, Berlin.

Wilkins, A.J., Nimmo-Smith, I., Slater, A.I., and Bedocs, L. (1988) "Fluorescent Lighting, Headaches and Eyestrain." In: Proceedings of the CIBSE National Lighting Conference, Cambridge (UK), pp. 188-196. 